\title{
Tension Pneumocephalus with Diplegia and Deterioration of Consciousness
}

\author{
Harald Prüss $^{a} \quad$ Randolf Klingebiel ${ }^{a, b} \quad$ Matthias Endres ${ }^{a}$ \\ Departments of a Neurology and beuroradiology, Charité - University Medicine \\ Berlin, Campus Mitte, Berlin, Germany
}

\section{Key Words}

Tension pneumocephalus · Mount Fuji sign · Emergency · Diplegia

\begin{abstract}
Tension pneumocephalus results from intracranial air under pressure as a rare complication after head injury or craniofacial surgery. A 58-year-old man underwent ethmoid sinus surgery and subsequently developed rapidly progressive global headache, restlessness, diplegia with sensory loss, and deterioration of the conscious level. A head CT demonstrated extensive pneumocephalus with gross compression of the brain. The frontal retention of air caused widening of the interhemispheric fissure leading to a peaked appearance of the frontal poles, referred to as the 'Mount Fuji sign'. Surgical revision of a dural air leak resulted in rapid improvement and full clinical resolution. Early diagnosis of tension pneumocephalus and emergent surgical treatment are crucial to prevent life-threatening deterioration.
\end{abstract}

\section{Case Report}

Intracranial air is common after head injury or craniofacial surgery and is known as pneumocephalus. Usually, it does not require surgical treatment; however, tension pneumocephalus results from intracranial air under pressure as a rare complication [1]. In exceptional cases, posttraumatic tension pneumocephalus can proceed to rapid deterioration and death.

A 58-year-old man underwent ethmoid sinus surgery and subsequently developed rapidly progressive global headache, restlessness, and diplegia with sensory loss. He was admitted to the intensive care unit due to deterioration of the conscious level. A CT scan of the head demonstrated an extensive pneumocephalus with intracranial air causing a mass effect and gross compression of the brain (fig. 1a) due to presumed dural air leak from a defect in the cribriform plate (arrow). This was surgically revised with release of intracranial tension and a duraplastic procedure, followed by rapid improvement and full clinical resolution within $36 \mathrm{~h}$.

Both mechanisms that have been proposed for the development of pneumocephalus may have taken place in our patient: the 'ball-valve' and the 'inverted pop bottle' effect [1]. It has been postulated that air passes through the dural tear by elevated upper airway pressure that occurs during coughing or sneezing - the ball-valve effect. The other mechanism operates when cerebrospinal fluid leaves the intracranial 


\begin{tabular}{c|l|l|l}
$\begin{array}{c}\text { Case Reports in } \\
\text { Neurology }\end{array}$ & $\begin{array}{l}\text { Case Rep Neurol 2011;3:48-49 } \\
\text { DOl: 10.1159/000324824 }\end{array}$ & $\begin{array}{l}\text { Published online: } \\
\text { February 14, 2011 }\end{array}$ & $\begin{array}{l}\text { O 2011 S. Karger AG, Basel } \\
\text { ISSN 1662-680X } \\
\text { www.karger.com/crn }\end{array}$ \\
\hline
\end{tabular}

space through the dural leak and the resulting negative pressure causes air to rush in, similar to an inverted pop bottle. In our case, the frontal retention of air caused widening of the interhemispheric fissure leading to a peaked appearance of the frontal poles commonly referred to as the 'Mount Fuji sign' [2] (fig. 1b).

Generally, the most common symptoms of tension pneumocephalus are altered consciousness, headache, generalized convulsions, or restlessness [3], but even cardiac arrest caused by tension pneumocephalus has been reported [4]. Besides the typical symptoms, our patient developed marked weakness of both legs with inability to walk after a few hours, most likely due to air compression of the interhemispheric leg motor cortex area.

The present case report underlines that early diagnosis of tension pneumocephalus and emergent surgical treatment are crucial to prevent life-threatening deterioration.
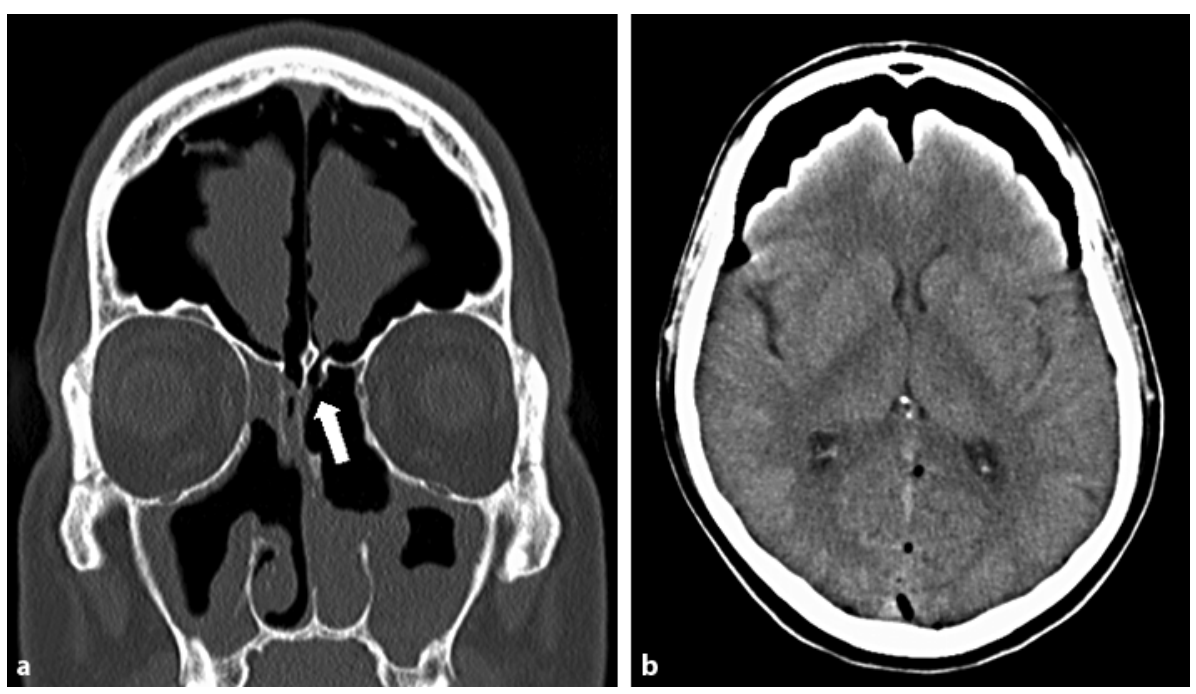

Fig. 1. Entry of air through a bony defect (arrow) leading to compression of the brain (a). Frontal accumulation of air causing widening of the interhemispheric fissure (b).

\section{References}

1 Clevens RA, Marentette LJ, Esclamado RM, et al: Incidence and management of tension pneumocephalus after anterior craniofacial resection: case reports and review of the literature. Otolaryngol Head Neck Surg 1999;120:579-583.

2 Sadeghian H: Mount Fuji sign in tension pneumocephalus. Arch Neurol 2000;57:1366.

-3 Satapathy GC, Dash HH: Tension pneumocephalus after neurosurgery in the supine position. Br J Anaesth 2000;84:115-117.

4 Thiagarajah S, Frost EA, Singh T, Shulman K: Cardiac arrest associated with tension pneumocephalus. Anesthesiology 1982;56:73-75. 